\title{
Mutational analysis of the BRCA2 gene in breast carcinoma patients of Kashmiri descent
}

\author{
SHIEKH GAZALLA AYUB ${ }^{1}$, SHABHAT RASOOL ${ }^{1}$, TAHA AYUB $^{2}$, SAQUIB NAVEED KHAN $^{3}$, \\ KHURSHEED ALAM WANI ${ }^{4}$ and KHURSHID IQBAL ANDRABI ${ }^{1}$
}

\author{
${ }^{1}$ Department of Biotechnology, University of Kashmir, Kashmir 190006; ${ }^{2}$ Government Medical College, Srinagar 190010; \\ Departments of ${ }^{3}$ Accident and Emergency and ${ }^{4}$ Surgery, Sheri-Kashmir Institute of Medical Sciences, \\ Soura, Srinagar, Jammu and Kashmir 190011, India
}

Received May 14, 2013; Accepted November 27, 2013

DOI: $10.3892 / \mathrm{mmr} .2013 .1862$

\begin{abstract}
Breast cancer demonstrates geographical and ethnic variation in its incidence reflecting the effect of local environmental conditions and lifestyle. The genesis of the disease has further been complexed by the involvement of a number of genes with small effects and above all by population heterogeneity. Accordingly, variations in genes, including breast cancer 1, early onset (BRCA1)/breast cancer 2, early onset (BRCA2), that have been markedly associated with the breast cancer phenotype exhibit a scattered mutational pattern in different populations. The present study was aimed to analyze the sequence variations in BRCA2 gene in a case control manner in ethnically pure Kashmiri population using PCR. Sequencing of BRCA2 exons revealed the presence of five sequence variations, four of which present in exon 11 alone were somatic and one was germline located in the U-terminal region (UTR) of exon 2. Out of these, the two somatic mutations comprised of substitutions, one representing a missense mutation leading to an amino-acid substitution at codon 991 and the other was a silent mutation at codon 1131, whereas the other two mutations located in exon 11 represented a loss of polymorphism. Codons for amino acid position 846 and 868 were demonstrated to be heterozygous polymorphic variants in $66 \%$ of the normal breast tissue samples, whereas the heterozygous polymorphic variant codons at the two loci were replaced by a homozygous genotype in associated tumor tissue in $88 \%$ of cases. These two mutations were always linked. Germline variation observed in exon 2 was located in the UTR region at contig position 13870572 (rs1799943). Other screened exons of BRCA2 did not demonstrate any sequence variation.
\end{abstract}

Correspondence to: Professor Khurshid Iqbal Andrabi, Department of Biotechnology, University of Kashmir, Hazratbal, Srinagar, Jammu and Kashmir 190006, India

E-mail: andraik@kashmiruniversity.net

Abbreviations: IBC, inflammatory breast carcinoma; IDC, infiltrating ductal carcinoma; UTR, U-terminal region

Key words: breast cancer, BRCA2, mutation, polymorphism, Kashmir, ethnic, India
These variations may contribute to breast cancer susceptibility along with variations in other low penetrating genes in sporadic types of breast cancer in this cohort of the population.

\section{Introduction}

Breast cancer is the most common malignancy affecting females worldwide (1), accounting for $25 \%$ of all new cases of cancer. One in eight to one in 12 females are likely to suffer from breast cancer during their lifetime in developed countries and one in 22 is likely to develop the disease in developing countries. Breast cancer incidence rate varies at least ten-fold worldwide (2), largely due to a range of socio-economic, reproductive, hormonal, nutritional and genetic factors (3). Breast cancer is the second most common cancer in females following cervical cancer in India and has replaced cervical cancer among females in Indian cities $(4,5,6)$. It is estimated that there are $\sim 85,000$ new cases of breast cancer in India annually constituting $25 \%$ of total cancer cases (4). Although epidemiologic investigations have identified numerous risk factors for breast cancer, including early menopause (7), alcohol and tobacco consumption (8), radiation exposure (9), obesity $(10)$, physical activity $(11,12)$, urbanization (13), sedentary lifestyle (12), dietary fat (14), changes in reproductive patterns $(15,16)$ including delayed childbearing and having fewer children, nulliparity $(17,18)$, lack of breast-feeding $(16,18,19)$, multiple abortions (19) and post-menopausal hormone replacement therapy (20), genetic factors have also been identified as a major contributor to the risk of developing this disease.

Breast cancer 2, early onset (BRCA2) was the second breast cancer susceptibility gene to be discovered and is important in the error-free repair of DNA double strand breaks as well as transcriptional regulation (21-23). In normal cells, BRCA2 ensures the stability of the cell's genetic material (DNA) and prevents uncontrolled cell growth. Germline mutations in BRCA2 are predicted to account for $\sim 35 \%$ of families with multiple cases of early onset female breast cancer and are also associated with an increased risk of male breast cancer and ovarian cancer $(24,25)$. The spectrum of BRCA2 mutations has been characterized in different populations worldwide, with significant variation of the relative contribution of this gene to breast cancer between populations $(26,27)$. A 
database of the mutation spectra of the BRCA2 gene has been established (Breast Cancer Information Core, BIC; database; http://research.nhgri.nih.gov/projects/bic/) and to date a large number of distinct variations in this gene have been registered in the BIC database. However, studies on BRCA2 mutations have mainly involved hereditary breast and ovarian cancer families which represent only a small proportion of total cases, whereas studies focusing on sporadic breast cancer representing the majority of total breast cancer cases remain relatively sparse.

Kashmir constitutes an ethnically pure population as it is distinct from other regions due to intra-community marriages, food habits, location, local environment and culture, thus providing a genetically pure group of people, which reduces the risk of multiple alleles that mixed populations tend to harbor. The present study has therefore been set out to examine the frequency of mutations in BRCA2 in a panel of 100 breast cancer patients from the geographically and ethnically distinct population of Kashmir. Studies that are population based may give a more representative estimate, however only a few relatively small studies of this type have been published from the Kashmir population.

\section{Materials and methods}

Patients and samples. After obtaining approval from the Ethics Committee of Sher-I-Kashmir Institute of Medical Sciences (Srinagar, Jammu and Kashmir, India), patients presenting for treatment of breast cancer for the first time at the Sher-I-Kashmir Institute of Medical Sciences were recruited for the study with prior informed consent. Patients underwent fine needle aspiration cytology and histopathological examination to establish the clinical profile. Blood samples and surgically resected breast tissue (which included tumor tissue, normal tissue and lymph node/s wherever involved) were collected from 245 sporadic breast cancer cases. All samples were snap-frozen at $-70^{\circ} \mathrm{C}$ until analysis. A questionnaire was used to collect the information on clinico-epidemiological characteristics, including age, family history of disease, body mass, menopause status, site of tumor, marital status, provisional diagnosis, lymph node/s involved and the clinical tumor stage of patients.

DNA extraction and PCR amplification. High molecular weight genomic DNA from tissue samples of breast cancer patients and blood samples were isolated by proteinase $\mathrm{K}$ digestion and phenol-chloroform extraction. Air-dried DNA pellet was resuspended in Tris-EDTA and the DNA concentration was measured by a spectrophotometric method.

PCR amplification using 11 sets of primer pairs was used to amplify exons 2, 9, 11.1, 11.2, 11.3, 11.4, 11.5, 11.6 (for 6174delT), 18, 20 and 25 of BRCA2 as follows. Exon 2: F, CTC AGT CAC ATA ATA AGG AAT; R,ACA CTG TGA CGT ACT GGG TTT T. Exon 9: F, CTA GTG ATT TTA AAC TAT AAT TTT G, R, GTT CAA CTA AAC AGA GGA CT. Exon 11.1: F, ATT TAG TGA ATG TGA TTG ATG G; R, TGA TTC TTT GCC TCT AGA AA. Exon 11.2: F, CAA AAG TGG AAT ACA GTG ATA C; R, TCT GTT TCA TGA AGT TCC TT. Exon 11.3: F, TTC AAA AAT AAC TGT CAA TCC; R, TCT TTG AAG AAC ATT TTG CT. Exon 11.4: F, ACA AAT GGG CAG GAC TCT TAG G; R, TCT GCA TTC CTC AGA AGT GG; Exon 11.5: F, GAA TCA GGA AGT CAG TTT GA; R, TAT CAG TTG
GCA TTT ATT ATT TTT. Exon 11.6: F, GGG AAG CTT CAT AAG TCA GTC; R, TTT GTA ATG AAG CAT CTG ATA CC; Exon 18: F, GTG ACT TGT TTA AAC AGT GGA A; R, ATT GAG CAT CCT TAG TAA GCA; Exon 20: F, AAG TGA ATA TTT TTA AGG CAG TT; R, TAT ATG GTA AGT TTC AAG AAT; Exon 25: F, TTA GAG TTT CCT TTC TTG CAT C; R, AAG CTA TTT CCT TGA TAC TGG A. PCR was performed in an Applied Biosysytem Minicycler at a respective annealing temperature. PCR assays were conducted in a reaction volume of $50 \mu \mathrm{l}$ containing 100-120 ng of genomic DNA, $0.2 \mathrm{mM}$ of dNTPs (Sigma, St. Louis, MO, USA), 1X PCR buffer (Sigma), $0.5 \mathrm{U}$ of Taq DNA Polymerase (Sigma) and $10 \mathrm{pmol}$ of each primer (Sigma). Amplification was performed for 30-35 cycles in a thermal cycler (Applied Biosystems Inc., Foster City, CA, USA) with each cycle consisting of $30 \mathrm{sec}$ at $95^{\circ} \mathrm{C}, 45 \mathrm{sec}$ at the optimal annealing temperature and $45 \mathrm{sec}$ at $72^{\circ} \mathrm{C}$, with a 10 min extension at $72^{\circ} \mathrm{C}$ following the last cycle.

Statistical analysis. All statistical analyses were performed using the SPSS program. $\mathrm{P} \leq 0.05$ was considered to indicate a statistically significant difference. The prevalence of BRCA2 mutations obtained in Kashmiri patients was compared with compiled data for breast cancer in the BIC database (www.ngri.nih.gov/intramuraresearch/BIC) and other areas, including India.

\section{Results}

Mutational screening of commonly mutated exons $(2,9,11,18,20,25)$ of BRCA2 in 242 tumor and associated normal samples of Kashmiri breast cancer patients revealed a total of five variations, out of which four were somatic and one was germline in nature. All somatic variations were located in exon 11 and the germline variation was observed in the UTR region of exon 2.

Genotype analysis revealed the presence of the heterozygous genotype at codon positions 846 (TCC/TCA) and 868 (CCT/ACT) in $62 \%(150 / 242)$ of the normal breast tissue samples, whereas the remaining 38\% (92/242) had homozygous genotype (TCC/TCC at codon 846 and CCT/CCT at codon 868). It was observed that the heterozygous variants were replaced by homozygous genotype TCA/TCA at codon position 846 and ACT/ACT at codon position 868, dissimilar from the one present in normal samples in $88 \%$ of the associated tumour samples. It was also observed that the duo change was linked and none of the two were individually replaced in any of the samples (Fig. 1). C>A variation at amino acid position 846 is a silent variation and has already been reported (rs11571654), whereas the missense variation at amino acid position 868 leading to the replacement of proline by threonine appeared to be novel.

Mutations observed in exon 11 at codon position 991 and 1131 are A:T>G:C transitions (Fig. 2). A somatic mutation at amino acid position 991 (AAC/GAC) leading to the replacement of asparagine with aspartic acid was present in 24\% (58/242) of all cancer cases, whereas the A to G (AAA/AAG) transition at amino acid position 1131 was a silent mutation and was demonstrated in $20 \%$ (48/242) of all cancer patients. The germline variation $\mathrm{G}: \mathrm{C}>\mathrm{A}: \mathrm{T}$ transition observed in the UTR region of exon 2 was observed in 32\% (77/242) of all patients. The germline nature of the variation observed in exon 2 was established as the variation observed in the tumor was also identified in 
Table I. Association of two associated mutations at codon position '846 (rs11571654) and 868 (Novel)' and codon position 991 (rs1799944) on exon 11 of BRCA2 with clinico-epidemiological features of sporadic breast cancer patients of Kashmir $(\mathrm{n}=150 \& 242)$.

\begin{tabular}{|c|c|c|c|c|c|c|}
\hline Features & $\begin{array}{c}\text { Codon position } \\
846 \text { and } 868\end{array}$ & P-value & Odds Ratio & Codon position 991 & P-value & Odds Ratio \\
\hline \multicolumn{7}{|l|}{ Age (years) } \\
\hline$\leq 45$ years & $48 / 60$ & 0.65 & 1.38 & $29 / 97$ & 0.46 & 1.7 \\
\hline$\geq 45$ years & $84 / 90$ & & $(0.1-17.67)$ & $29 / 145$ & & $(0.1-4.7)$ \\
\hline \multicolumn{7}{|l|}{ Environment } \\
\hline Rural & $108 / 120$ & 0.5 & 0.44 & $54 / 218$ & 0.65 & 0.75 \\
\hline Urban & $24 / 30$ & & $(0.032-6.18)$ & $4 / 24$ & & $(0.06-8.38)$ \\
\hline \multicolumn{7}{|l|}{ Menopause status } \\
\hline Pre-menopausal & $48 / 60$ & 0.65 & 1.38 & 29/97 & 0.46 & 1.7 \\
\hline Post-menopausal & $84 / 90$ & & $(0.1-17.67)$ & $29 / 142$ & & $(0.26-10.92)$ \\
\hline \multicolumn{7}{|l|}{ Breast involved } \\
\hline Right & $42 / 48$ & 0.69 & 1.4 & $4 / 16$ & 0.65 & 1.08 \\
\hline Left & $90 / 102$ & & & $8 / 34$ & & $(0.15-7.64)$ \\
\hline \multicolumn{7}{|c|}{ Provisional diagnosis } \\
\hline IDC & $132 / 150$ & N/A & & $58 / 242$ & N/A & N/A \\
\hline IBC & $0 / 0$ & & & & & \\
\hline Paget's disease & $0 / 0$ & & & & & \\
\hline \multicolumn{7}{|c|}{ Lymph nodes involved } \\
\hline Yes & $96 / 108$ & 0.64 & 0.75 & $10 / 36$ & 0.44 & 0.43 \\
\hline No & $36 / 42$ & & $(0.05-9.8)$ & $2 / 14$ & & $(0.04-4.5)$ \\
\hline \multicolumn{7}{|l|}{ Tumor stage } \\
\hline II $(a, b)$ & $42 / 60$ & 0.54 & $0.5(0.03-6.6)$ & $19 / 97$ & 0.66 & $1.14(0.12-10.38)$ \\
\hline III $(a, b)$ & $54 / 54$ & 0.3 & $4(0.27-58.56)$ & $19 / 87$ & 0.53 & $1.75(0.17-17.68)$ \\
\hline IV & $36 / 36$ & 0.48 & $2(0.2-19.9)$ & $20 / 58$ & 0.48 & $2(0.2-19.9)$ \\
\hline
\end{tabular}

the adjacent normal tissue, blood and lymph node of the same patient. The germline nature of the heterozygous polymorphic variants at position 846 and 868 in normal breast tissue was established as the variants were also observed in blood and lymph node of the same patient.

The presence of BRCA2 mutations when compared with various clinico-epidemiological attributes of sporadic breast cancer patients demonstrated an association with age, menopausal stage and advanced clinical stage of the disease, although this was not statistically significant. However, there was no association with early onset and late onset breast cancer cases, positive lymph node status and the breast involved.

\section{Discussion}

Second only to lung carcinoma, breast cancer is a leading cause of cancer mortality among females in the western hemisphere. The lifetime risk of developing breast cancer and the overall prognosis following diagnosis of the disease and the likelihood of response to specific therapy is able to be determined by exploiting the distinct characteristics of breast carcinoma. It is quite evident that a myriad of factors, including steroid hormones along with their receptors, peptide growth factors, oncogenes and tumor suppressor genes are crucial in the transformation of breast tissue (28). The contribution of the BRCA2 gene to the incidence and prevalence of breast cancer is well established worldwide $(29,30,31,32)$. However, how important BRCA2 is in pre-disposing Indians to breast cancer is not well explored and to the best of our knowledge no such study has been performed in the Kashmiri population. The aim of the present study was to assess the mutational spectrum and frequency of BRCA2 mutations as well as to explore the existence of population specific mutations, if any, in Kashmiri breast cancer patients. Direct nucleotide sequencing revealed somatic mutations at codon positions 846 (rs11571654), 868 (novel), 991 (rs1799944) and 1131 (rs1801406), and one germline variation in the UTR region of exon 2 with rs1799943 in the BRCA2 gene.

Our studies revealed that a polymorphism at codon 868 lead to translation into either proline or threonine in $62 \%$ of the normal breast tissue samples, whereas only proline was present in $38 \%$ of the samples. The replacement of the heterozygous amino acid pair proline/threonine with threonine/threonine at codon position 868 is a novel change. This change was always linked with the change at codon 846 , where also a heterozygous set of codons (TCC/TCA), although coding for the same amino acid serine (silent mutation), was replaced by a homozygous pair of codons (TCA/TCA). These changes were observed in the N-terminal region of exon 11 and lie extremely close to the highly conserved BRCA1 repeat. This amino acid change may be extremely significant as proline, belonging to the non-polar aliphatic group, has been replaced by threonine belonging to a group of polar and uncharged amino acids. The proline reduces the structural flexibility of the protein at that position as the secondary amino (imino) group of proline is held in a rigid conformation, thus this substitution could be important in altering the functional properties of the protein and may contribute significantly in making Kashmiri population more susceptible to breast cancer.. Although the genotypic change at codon position 846 is a silent change, the strong linkage of the changes at the two codon positions could be very important and needs to be further elucidated. 
A

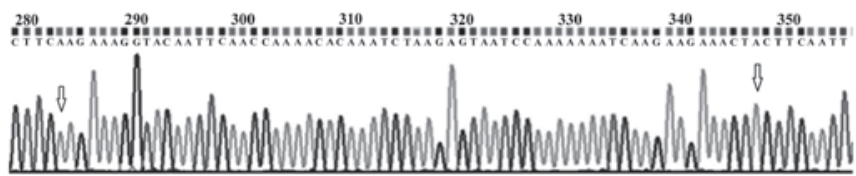
B

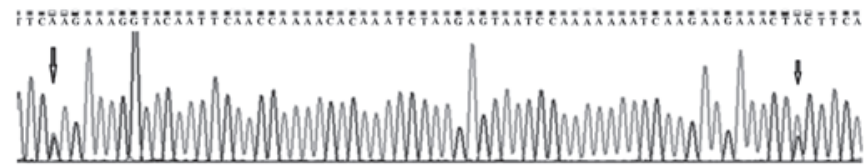

C

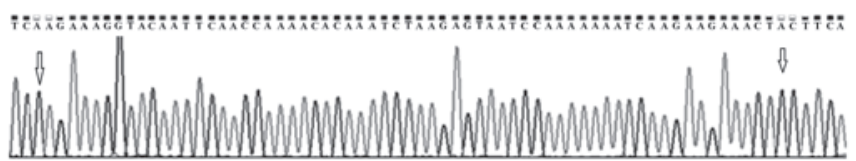

Figure 1. (A) Partial chromatograms representing different phenotypes (indicated by arrows) of two associated mutations at positions 846 and 868 (A) Normal heterozygous phenotype observed in $62 \%$ of normal samples. (B) Homozygous phenotype observed in $88 \%$ of associated tumor samples. (C) Homozygous phenotype observed in $38 \%$ of normal samples and $12 \%$ of tumor samples.

It may be possible that the duo change is actually important in the transition from normal to cancerous breast tissue.

The amino acid change at codon 991 observed in $24 \%$ $(58 / 242)$ of the patients is a missense change substituting asparagine by aspartic acid. This amino acid lies in the BRCA1 repeat of exon 11, which constitutes one of the 4 repeats of the BRCA2 protein that appear to be highly conserved in mammals $(33,34)$. These BRC repeats in the BRCA2 protein aid in directly binding BRCA2 to RAD51, a critical protein for DNA recombination and double-stranded DNA repair $(35,36,37)$. The association of this missense mutation with breast cancer susceptibility has been demonstrated in the Cyprist population (38). The authors demonstrated a significant association of this change with an increased risk of breast cancer $(\mathrm{P}=0.01$ and $\mathrm{P}=0.0076)$. A moderately strong association of this BRCA2 polymorphism with malignant melanoma risk has also been demonstrated ( $\mathrm{P}=0.02$ following Bonferroni correction) (39). In silico prediction methods also suggest that this is a non-tolerated amino acid substitution within the limits of confidence in the alignments (40). The role of this SNP in breast cancer has also been investigated in the multi-ethnic cohort study and no association has been demonstrated (41). The germ $\neg$-line variation observed in the UTR region of exon 2 was present in $32 \%(77 / 242)$ of total patients. This variation observed is only 25 bases ahead of the initiation codon in exon 2 , thus there is a high probability that it may be important in RNA processing. However, whether this polymorphic variant represents a simple population variant or is important in Kashmiri breast cancer patients needs to be elucidated by further studies. No mutation of either germ-line or somatic nature was observed in any other exons screened. The comparison of various clinicoepidemiological attributes of sporadic breast cancer patients to these somatic mutations demonstrated an association with early onset and late onset breast cancer cases, menopausal status and advanced clinical stage (III and IV) of the disease. However,

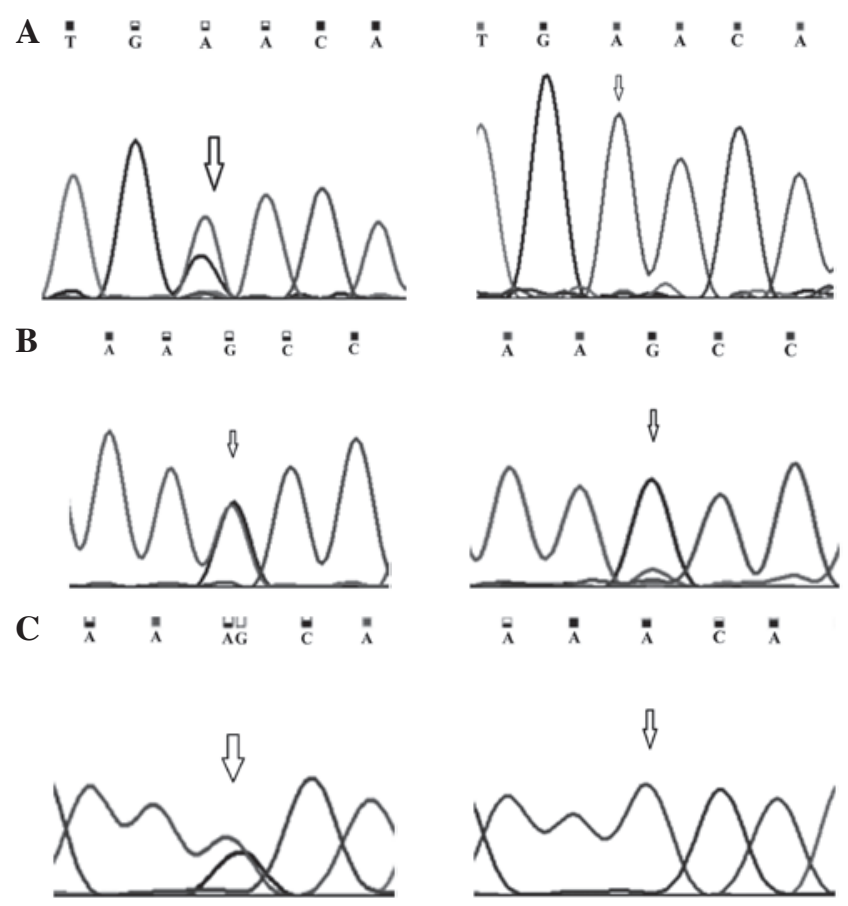

Figure 2. Partial chromatograms representing mutant and normal profile (shown by arrows, left and right, respectively) at (A) codon position 991 in exon 11; (B) codon position 1131 in exon 11 and (C) codon position 1131 (contig position, 13870572) in exon 11.

there was no significant association of BRCA2 mutations with positive lymph node status and the breast involved.

Although no insertion or deletion was demonstrated in any case, the missense variations observed in our population may not be nullified as the prevailing polygenic model of breast cancer risk suggests that a moderate number of genes, each conferring a small amount of risk alone (relative risk 1.3-1.5), together combines multiplicatively, resulting in modest susceptibility to breast cancer (42). According to this model, more than 100 genes may contribute to breast cancer susceptibility. Each gene may have either common or rare variants and females carrying more variant alleles may be at a greater risk than those carrying fewer. Thus, there is a high possibility that these somatic missense variants may be contributing to breast cancer susceptibility along with variations in other low penetrating genes in sporadic type of breast cancer in this population cohort. Distinct characteristics of breast carcinoma may be exploited for determining the lifetime risk of development of the disease, the overall prognosis following a diagnosis of breast carcinoma and the likelihood of response to specific therapy (32). The findings from the present study add to the body of knowledge concerning the prevalence and nature of BRCA2 mutations in the ethnic Kashmiri population and may inform strategies for genetic cancer risk assessment (43). Additionally, increased understanding of breast carcinoma pathways may enhance our ability to produce targeted approaches for the prevention of this disease.

\section{Acknowledgements}

This study was supported in part by the Council of Scientific and Industrial Research (no. 9/251(12)/2004-EMR-1) and the Department of Biotechnology, University of Kashmir 
(Srinagar, Jammu and Kashmir, India). The authors gratefully acknowledge Dr Tariq Jan, Department of Statistics, University of Kashmir (Srinagar, Jammu and Kashmir, India) for his assistance with the statistical analysis of the study.

\section{References}

1. Parkin DM: International variation. Oncogene 23: 6329-6340, 2004.

2. Parkin DM, Whelan SL, Ferlay J, Raymond L and Young J (eds): Cancer Incidence in Five Continents. Vol 8. IARC Press, Lyon, 1997.

3. McPherson K, Steel CM and Dixon JM: ABC of breast diseases. Breast cancer-epidemiology, risk factors, and genetics. BMJ 321: 624-628, 2000

4. Indian Council of Medical Research: National Cancer Registry programme: Consolidated report of the population based cancer registries 1990-1996, Indian Council of Medical Research, New Delhi, 2001.

5. Mittra I, Badwe RA, Desai PB, Yeole BB and Jussawalla DJ: Early detection of breast cancer in developing countries Lancet 1: 719-720, 1989.

6. Rao DN and Ganesh B: Estimate of cancer incidence in India in 1991. Indian J Cancer 35: 10-18, 1998

7. Magnusson C, Baron J, Persson I, Wolk A, Bergström R, Trichopoulos D and Adami HO: Body size in different periods of life and breast cancer risk in post-menopausal women. Int J Cancer 76: 29-34, 1998.

8. Hamajima N, Hirose K, Tajima K, et al: Alcohol, tobacco and breast cancer-collaborative reanalysis of individual data from 53 epidemiological studies, including 58,515 women with breas cancer and 95,067 women without the disease. Br J Cancer 87: 1234-1245, 2002.

9. Gervais-Fagnou DD, Girouard C, Laperriere N, Pintillie M and Goss PE: Breast cancer in women following supradiaphragmatic irradiations for Hodgkin's disease. Oncology 57: 224-231, 1999.

10. Calle EE, Rodriguez C, Walker-Thurmond $\mathrm{K}$ and Thun MJ: Overweight, obesity, and mortality from cancer in a prospectively studied cohort of U.S. adults. N Engl J Med 348: 1625-1638, 2003.

11. Bray F, McCarron P and Parkin DM: The changing global patterns of female breast cancer incidence and mortality. Breast Cancer Res 6: 229-239, 2004.

12. Datta K and Biswas J: Influence of dietary habits, physical activity and affluence factors on breast cancer in East India: a case-control study. Asian Pac J Cancer Prev 10: 219-222, 2009.

13. McMichael AJ and Giles GG: Cancer in migrants to Australia: extending the descriptive epidemiological data. Cancer Res 48: 751-756, 1988.

14. Schulz M, Hoffmann K, Weikert C, Nöthlings U, Schulze MB, and Boeing $\mathrm{H}$ : Identification of a dietary pattern characterized by high-fat food choices associated with increased risk of breast cancer: the European Prospective Investigation into Cancer and Nutrition (EPIC)-Potsdam Study. Br J Nutr 100: 942-946, 2008.

15. Collaborative Group on Hormonal Factors in Breast Cancer: Breast cancer and breastfeeding: collaborative reanalysis of individual data from 47 epidemiological studies in 30 countries, including 50302 women with breast cancer and 96973 women without the disease. Lancet 360: 187-195, 2002.

16. Lord SJ, Bernstein L, Johnson KA, et al: Breast cancer risk and hormone receptor status in older women by parity, age of first birth, and breastfeeding: a case-control study. Cancer Epidemiol Biomarkers Prev 17: 1723-1730, 2008

17. Winer EP, Morrow M, Osborne CK and Harris JR: Cancer of the breast. Section 2, Malignant Tumors of the Breast. In: Cancer: Principles \& Practice of Oncology. DeVita VT (ed). Vol 2. 6th edition. J.B. Lippincott, Philadelphia, pp1651-1659, 2000

18. Huo D, Adebamowo CA, Ogundiran TO, Akang EE, Campbell O, Adenipekun A, Cummings S, Fackenthal J, Ademuyiwa F, Ahsan H and Olopade OI: Parity and breastfeeding are protective against breast cancer in Nigerian women. Br J Cancer 98: 992-996, 2008.

19. Zeng Y, Xu MS, Tan SQ and Yin L: Analysis of the risk factors of breast cancer. Nan Fang Y Yi Ke Da Xue Xue Bao 30: 622-623, 2010 (In Chinese)

20. Beral V: Breast cancer and hormone-replacement therapy in the Million Women Study. Lancet 362: 419-427, 2003.

21. Moynahan ME, Pierce AJ and Jasin M: BRCA2 is required for homology-directed repair of chromosomal breaks. Mol Cell 7: 263-272, 2001
22. Davies AA, Masson JY, McIIwraith MJ, Stasiak AZ, Stasiak A, Venkitaraman AR and West SC: Role of BRCA2 in control of the RAD51 recombination and DNA repair protein. Mol Cell 7: 273-282, 2001

23. Pellegrini L, Yu DS, Lo T, Anand S, Lee M, Blundell TL and Venkitaraman AR: Insights into DNA recombination from the structure of a RAD51-BRCA2 complex. Nature 420: 287-293, 2002.

24. Gayther SA, Mangion J, Russell P, Seal S, Barfoot R, Ponder BA, Stratton MR and Easton D: Variation of risks of breast and ovarian cancer associated with different germline mutations of the BRCA2 gene. Nat Genet 15: 103-105, 1997.

25. Thorlacius S, Olafsdottir G, Tryggvadottir L, Neuhausen S, Jonasson JG, Tavtigian SV, Tulinius H, Ogmundsdottir HM and Eyfjörd JE: A single BRCA2 mutation in male and female breast-cancer families from Iceland with varied cancer phenotypes. Nat Genet 13: 117-119, 1996.

26. Oddoux C, Struewing JP, Clayton CM, et al: The carrier frequency of the BRCA2 6174delT mutation among Ashkenazi Jewish individuals is approximately 1\%. Nat Genet 14: 188-190, 1996.

27. Thorlacius S, Sigurdsson S, Bjarnadottir H, Olafsdottir G, Jonasson JG, Tryggvadottir L, Tulinius H and Eyfjord JE: Study of a single BRCA2 mutation with high carrier frequency in a small population. Am J Hum Genet 60: 1079-1084, 1997.

28. Phillips KA: Current perspectives on BRCA1- and BRCA2-associated breast cancers. Inter Med J 31: 349-356, 2001.

29. Peto J, Collins N, Barfoot R, Seal S, Warren W, Rahman N, Easton DF, Evans C, Deacon J and Stratton MR: Prevalence of BRCA1 and BRCA 2 mutations in patients with early-onset breast cancer. J Natl Cancer Inst 91: 943-949, 1999.

30. Hopper JL, Southey MC, Dite GS, Jolley DJ, Giles GG, McCredie MR, Easton DF and Venter DJ: Population-based estimate of the average age-specific cumulative risk of breast cancer for a defined set of protein-truncating mutations in BRCA1 and BRCA2. Cancer Epidemiol Biomarkers Prev 8: 741-747, 1999.

31. Thorlacius S, Struewing JP, Hartge P, Olafsdottir GH, Sigvaldason H, Tryggvadottir L, Wacholder S, Tulinius H and Eyfjörd JE: Population-based study of risk of breast cancer in carriers of BRCA2 mutation. Lancet 352: 1337-1339, 1998.

32. Keen JC and Davidson NE: The biology of breast carcinoma. Cancer 97: 825-833, 2003

33. Bignell G, Micklem G, Stratton MR, Ashworth A and Wooster R The BRC repeats are conserved in mammalian BRCA2 proteins. Hum Mol Genet 6: 53-58, 1997.

34. Benson FE, Stasiak A and West SC: Purification and characterization of the human Rad51 protein, an analogue of E. coli RecA. EMBO J 13: 5764-5771, 1994.

35. Donovan JW, Milne GT and Weaver DT: Homotypic and heterotypic protein associations control Rad51 function in double-strand break repair. Genes Dev 8: 2552-2562, 1994.

36. Hays SL, Firmenich AA and Berg P: Complex formation in yeast double-strand break repair: participation of $\operatorname{Rad} 51, \operatorname{Rad} 52, \operatorname{Rad} 55$, and Rad57 proteins. Proc Natl Acad Sci USA 92: 6925-6929, 1995.

37. Loizidou MA, Michael T, Neuhausen SL, Newbold RF, Marcou Y, Kakouri E, Daniel M, Papadopoulos P, Malas S, Hadjisavvas A, Kyriacou K: DNA-repair genetic polymorphisms and risk of breast cancer in Cyprus. Breast Cancer Res Treat 115: 623-627, 2009.

38. Debniak T, Scott RJ, Górski B, et al: Common variants of DNA repair genes and malignant melanoma. Eur J Cancer 44: 110-114, 2008.

39. Fackenthal JD, Sveen L, Gao Q, et al: Complete allelic analysis of BRCA1 and BRCA2 variants in young Nigerian breast cancer patients. J Med Genet 42: 276-281, 2005.

40. Freedman ML, Penney KL, Stram DO, Le Marchand L, Hirschhorn JN, Kolonel LN, Altshuler D, Henderson BE and Haiman CA: Common variation in BRCA2 and breast cancer risk: a haplotype-based analysis in the Multiethnic Cohort. Hum Mol Genet 13: 2431-2441, 2004.

41. Saxena S, Szabo CI, Chopin S, Barjhoux L, Sinilnikova O, Lenoir G, Goldgar DE and Bhatanager D: BRCA1 and BRCA2 in Indian breast cancer patients. Hum Mutat 20: 473-474, 2002.

42. Hedau S, Jain N, Husain SA, Mandal AK, Ray G, Shahid M, Kant R, Gupta V, Shukla NK, Deo SSV and Das BC: Novel germline mutations in breast cancer susceptibility genes BRCA1, BRCA2 and p53 gene in breast cancer patients from India. Breast Cancer Res and Treat 88: 177-186, 2004

43. Weitzel JN, Lagos V, Blazer KR, Nelson R, Ricker C, Herzog J, McGuire C and Neuhausen S: Prevalence of BRCA mutations and founder effect in high-risk Hispanic families. Cancer Epidemiol Biomarkers Prev 14: 1666-1671, 2005. 